\title{
Using Continuous Simulation to Analyse the Downstream Impacts of Stormwater Management Ponds in the Sawmill River Watershed
}

\author{
Jeffrey T. Marvin \\ CBCL Limited, Halifax, Nova Scotia.
}

\begin{abstract}
Numerous hydraulic modeling studies carried out since the 1970s have demonstrated that the impact of flow detention is reduced as the flow is routed through the downstream watershed. Since stormwater management ponds delay and prolong peak flows, the downstream watershed receives increased runoff volumes and sustained peak flow rates from the ponds that can combine with other watershed drainage to increase downstream peak flows. This study uses continuous simulation modeling in PCSWMM to analyse the impacts of stormwater management ponds located throughout the Sawmill River watershed in Dartmouth, Nova Scotia on downstream peak flows near the watershed outlet at Sullivan's Pond. The effectiveness of the upstream ponds to maintain peak flows at Sullivan's Pond was analysed for all 903 historical rainfall events within a 61 y simulation period that had a 1 in 2 month probability of occurrence or greater, providing results for a full range of rainfall frequencies, rainfall amounts, rainfall durations and initial flow conditions. Pond effectiveness was evaluated for multiple model scenarios, which included varying the maximum overland flow lengths, the hydraulic conductivities of the soils, pond locations and development conditions. Overall, the study confirmed that the effectiveness of upstream ponds is reduced towards the watershed outlet, demonstrating the need for stormwater management practices that preserve runoff volumes and timing characteristics in addition to peak flows.
\end{abstract}

\section{Introduction}

Since the 1970s, conventional stormwater management practices in Canada and the United States have focused on preventing land development from increasing the peak flow rates of stormwater runoff during large rainfall events. These practices have traditionally been carried out by constructing stormwater management ponds (or detention ponds) downstream of development areas to collect, hold back and slowly release stormwater runoff at controlled flow rates. However, since land development creates impervious surfaces that reduce infiltration, and since runoff collected by these ponds cannot infiltrate into the ground, land development projects that use ponds to manage stormwater increase the total volume of runoff discharged to the downstream watershed. As a result, ponds delay and prolong peak stormwater flows, which can then combine with other watershed drainage and cause peak flows further downstream to increase (McCuen 1979).

More recently, the use of infiltration, evapotranspiration and rainwater harvesting practices for managing stormwater have become more common. These practices, which are commonly referred to in Canada and the United States as low impact development (LID), stormwater best management practices (BMPs) or green infrastructure $(\mathrm{Gl})$, instead aim to preserve the natural hydrology of a site by maintaining runoff volumes and water quality in addition to peak flows. However, in the Halifax Regional Municipality (HRM), the use of traditional stormwater management ponds to control runoff from new development has remained the standard for several years. Consequently, numerous ponds have been constructed throughout the municipality that are designed to maintain pre-development peak flow rates immediately downstream of their outlets.

This study analyses the impacts of stormwater management ponds in the Sawmill River watershed (Dartmouth, Nova Scotia) on downstream peak flows discharged to Sullivan's Pond. Peak flows are of particular concern at this location, as previous flooding from Sullivan's Pond during Hurricane Beth in 1971 caused widespread flooding damage to the Downtown Dartmouth area. A map of the Sawmill River watershed delineated to Sullivan's Pond is shown in Figure 1, and a map of the Sawmill River from Sullivan's Pond to Dartmouth Cove is shown in Figure 2. As shown in Figure 2, the Sawmill River is currently buried within a storm sewer system. This piped system was originally constructed in the early 1970 s following Hurricane Beth and is currently being replaced by an open channel and box culvert system that will have a higher flow capacity. One intent of this study is to therefore provide information on how potential flow control measures in the upstream watershed could impact the flows through this new channel. It is noted that Sawmill River is an unofficial name that has been used in recent

Marvin, Jeffrey T. 2018 Using Continuous Simulation to Analyse the Downstream Impacts of Stormwater Management Ponds in the Sawmill River Watershed. Journal of Water Management Modeling 26: C458. doi: 10.14796/JWMM.C458.

(c) CHI 2018. www.chijournal.org ISSN 2292-6062. 
years to describe the buried river downstream of Sullivan's Pond, whereas the river is part of the Shubenacadie Waterway system that spans from Dartmouth Cove in Halifax Harbour to the Cobequid Bay in the Bay of Fundy.

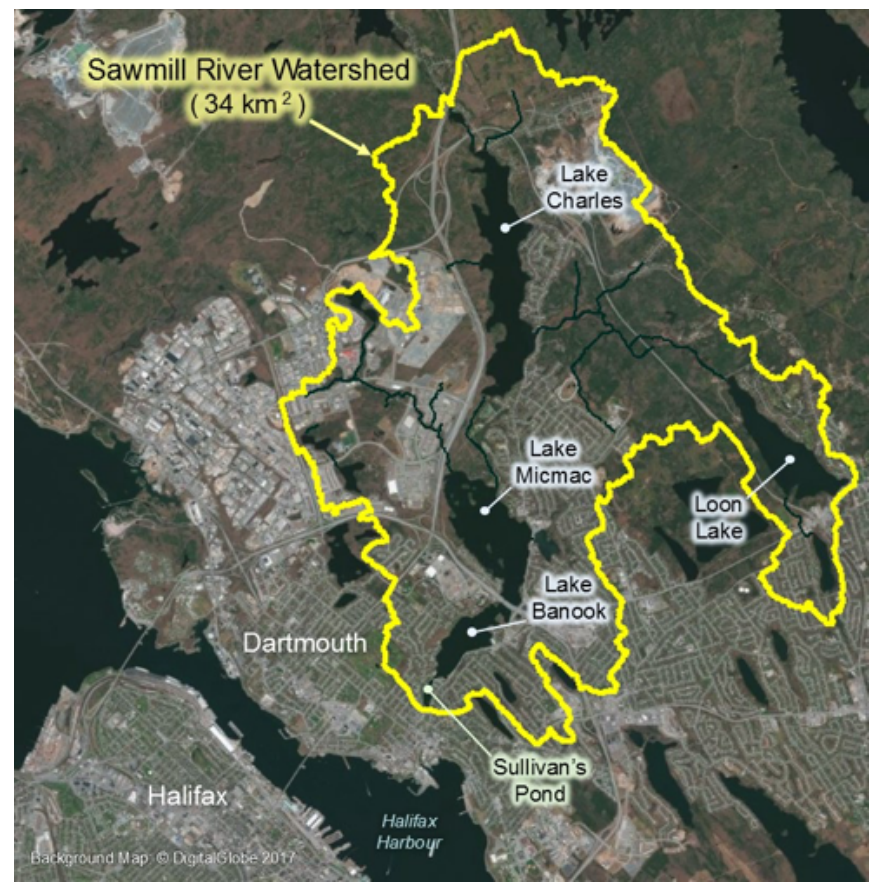

Figure 1 Sawmill River watershed delineation.

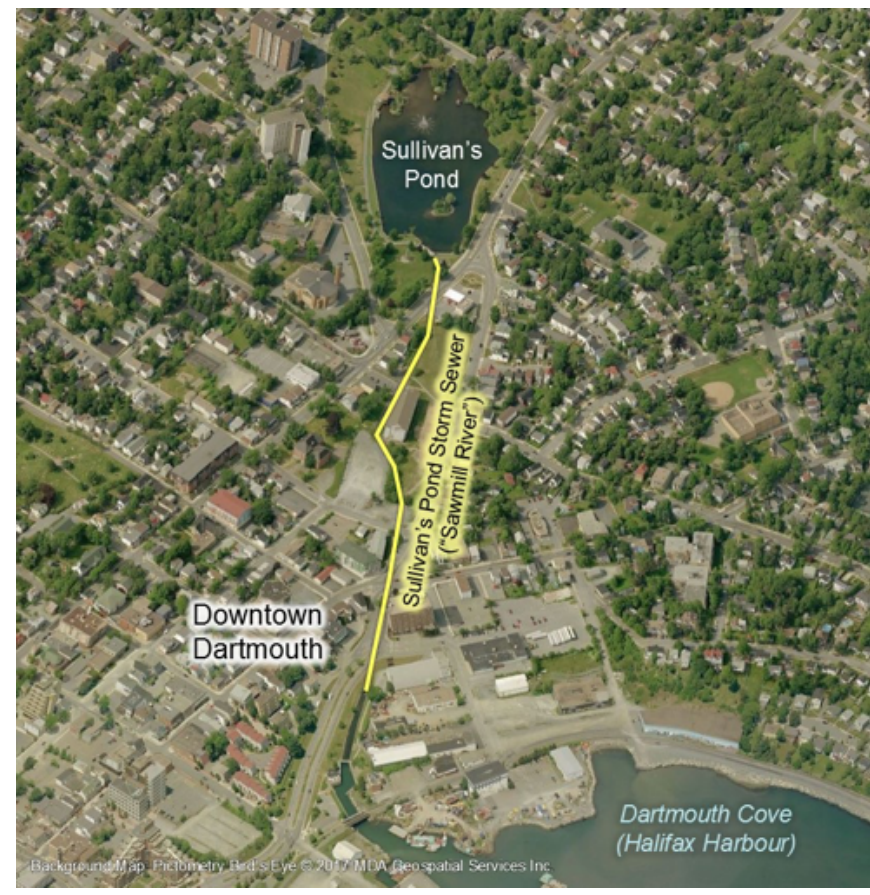

Figure 2 Existing storm sewer containing the Sawmill River.

Peak flows at Sullivan's Pond were estimated by carrying out long term continuous simulation modeling of the Sawmill River watershed with 61 y of rainfall data for various model scenarios. Whereas almost all previous modeling studies have analysed the downstream impacts of ponds based on synthetic design storm events or individual historical storm events, the use of continuous simulation modeling in this study instead allowed for a large number of historical rainfall events to be analysed. As a result, downstream peak flows could be evaluated under a full range of rainfall frequencies, rainfall amounts, rainfall durations and initial flow conditions.

\section{Previous Studies}

Numerous previous modeling studies carried out for both real and synthetic watersheds have demonstrated how the flow attenuation provided by ponds becomes reduced further downstream. Several of these studies have also evaluated solutions that involve optimizing pond locations and pond flow release designs. This section provides an overview of the previous research that has been carried out on the impacts of stormwater detention at a watershed scale and a discussion on the concerns and limitations associated with the proposed solutions.

\subsection{Studies that Evaluate the Downstream Im- pacts of Ponds}

One of the first documented concerns about the hydraulic impacts of stormwater detention at a watershed scale can be found in a report published in 1917 by the American Society of Civil Engineers (ASCE), which suggested that the efficiency of storage reservoirs and detention ponds diminishes as the distance from them increases (ASCE 1917). However, numerical modeling analyses that quantitatively evaluate the downstream impacts of stormwater detention were not carried out until the 1970s. The first published modeling study on the subject can be attributed to McCuen (1974), who found that if detention ponds are located near the watershed outlet, the delayed peak flows from the ponds may reach the outlet at the same time as the peak flow from the upper reaches of the watershed, which can result in increased peak flows at the outlet. McCuen (1979) then suggested that this is because the timing characteristics of storage in a natural watershed vary from those in ponds, and because ponds have no impact on controlling runoff volumes, which are increased by urbanization.

Since the 1970s, numerous other modeling studies involving different watersheds have confirmed that stormwater detention can lose its effectiveness further downstream. For example, a comprehensive study carried out by Emerson et al. (2005) found similar results using a calibrated model of a watershed that included 82 detention ponds. The inputs for geometry and outlet structures of the ponds were based on field measurements and the ponds were originally sized to maintain the 1 in $2 y$ to 1 in 100 y peak flows. The study found that minimal flow attenuation occurred at the watershed outlet as a result of the upstream ponds during large historical storm events, and that no flow attenuation occurred during smaller historical storm events. The study also evaluated the impact of capturing and removing specific runoff volumes at the beginning of the storm (simulating infiltration 
practices) and found that reducing runoff volumes significantly reduced downstream peak flows. These results therefore validated the suggestions made by McCuen (1979), who recommended using runoff volume control practices to maintain natural watershed storage characteristics.

While several other studies have arrived at similar conclusions for individual watersheds, Ferguson (1995) analysed 30 randomized watersheds with various development and detention pond conditions to produce generalized results. The study found that the use of stormwater detention in the watershed lengthened the duration of flow and was unable to reduce downstream peak flows to the desired levels. Similarly, Goff (2003) analysed stormwater detention for various synthetic watersheds by looking at different watershed shapes, watershed slopes, development sizes, development locations, development stages and development sequences. The model results presented by Goff (2003) showed that detention can be less effective for watersheds with elongated slopes, and detention can be less effective when ponds are located in the downstream region of the watershed. Goff (2003) also found that a uniform distribution of ponds in a watershed does not maintain pre-development peak flows and therefore suggested that stormwater management practices should instead focus on controlling runoff volumes to more closely maintain pre-development hydrographs.

\subsection{Studies on Pond Planning Tools}

As demonstrated by the above studies, analysing the downstream impacts of ponds within a given watershed requires developing hydrologic and hydraulic models of the entire watershed. However, the effort required for such a task is often significant and not practical for design. Thus, several studies have instead evaluated the use of simplified planning tools in lieu of developing complex models. For example, Hawley et al. (1981) developed a tool for estimating the flow and timing characteristics of a watershed using empirical equations to determine whether flows immediately downstream of a detention pond might increase. A similar tool was later developed by Del Giudice et al. (2014), where a simplified linear model approach was presented for estimating the downstream effectiveness of a detention pond system at any downstream location. Another example is the optimization model developed by Mays and Bedient (1982), which determined the minimum cost, size and location of detention basins along the main channel within a watershed. While the above tools simplify the modeling effort, they each have their limitations and are only intended for preliminary planning purposes.

\subsection{Studies on Pond Design Optimization}

Other studies have instead evaluated approaches that optimize pond design to maintain downstream peak flows. For example, Urbonas and Glidden (1983) evaluated multiple stormwater detention control policies by comparing the downstream impacts of ponds sized for different return periods. The study found that when ponds were sized for 1 in 10 y or 1 in 100 y design storms, the ability of the ponds to maintain downstream peak flows was effective only during the respective design storms. However, when ponds were sized for 1 in 2 y design storms, the downstream peak flows were not maintained during the 1 in $2 y$ design storm. A later study by Wulliman and Urbonas (2007) then assessed a full spectrum detention policy for a synthetic watershed in which pond volumes were designed to also capture the difference between post-development and pre-development runoff volumes. The study found that by releasing excess runoff volumes slowly over an extended period of time, flow attenuation was improved for smaller storm events.

Another approach for optimizing pond designs was presented by James et al. (1987), in which various detention pond scenarios along multiple stream orders within a synthetic watershed were modeled to provide general guidelines for sizing and locating detention facilities within a watershed. The study found that pre-development peak flows could be maintained downstream if the ponds were further increased in size. In this scenario, ponds would therefore be sized to attenuate post-development peak flows to below pre-development peak flow levels. The study also suggested that installing regional detention facilities is more effective than installing numerous smaller detention facilities in reducing downstream peak flows, as more storage volume is needed for when many small ponds are implemented in the upstream reaches.

As an alternative to optimizing ponds at all locations in the watershed at the same time, Ravazzani et al. (2014) presented an approach that optimizes the design of a new pond based on the existing flow attenuation provided by the previously constructed ponds in the watershed. The study developed an iterative procedure for sizing a system of ponds such that each successive pond would not increase downstream peak flows.

Finally, a master's thesis by Augustine (2015) investigated various policies for modifying pond flow controls based on their locations in the watershed. The flow rates released from the ponds were increased for ponds in the downstream half of the watershed and were either decreased or kept unchanged for ponds in the upstream half of the watershed. However, Augustine (2015) found that the proposed policies had almost no impact on peak flows at the watershed outlet and that the policies both increased and decreased peak flows along the various smaller tributaries.

\subsection{Limitations of Pond Design Optimization Approaches}

While optimizing the location or flow release controls of ponds in a watershed may help to maintain downstream peak flows, these potential solutions also present several limitations and concerns. One issue with pond design optimization is that it may require constructing larger ponds that are not economically feasible for developers (McCuen 1974; Augustine 2015). Moreover, optimizing ponds based on their location would cause unbalanced development policies, as the cost of development may be considerably 
higher for locations that require a large amount of stormwater detention. Additionally, while increasing the size of the ponds may help to reduce downstream peak flows, the larger pond volumes and release of flows over longer periods may increase the initial flow conditions during subsequent storm events.

The effectiveness of pond optimization would also be impacted by development sequencing in the watershed, as the optimized scenario assumes that all planned development and ponds in the watershed have been constructed. However, partial watershed development may result in peak flows that are higher than those associated with full watershed development (Shea 1996). Watershed development may therefore need to proceed from upstream to downstream to avoid the negative interim impacts, and such a phasing schedule may not be practical from a planning perspective. Additionally, all future development in the watershed would need to be anticipated at the initial planning stage. If pond flow release control optimization was instead carried out at the time of each new development, the detention volume required for the respective development area would vary depending on its order within the development sequencing in the watershed (Shea 1996). Furthermore, since the required size of a pond would not be known until the time of construction, it would be challenging for developers to anticipate pond costs. Finally, while pond optimization may successfully reduce peak flows at a specific downstream location, it may also increase peak flows at other downstream locations (Augustine 2015).

\subsection{Summary of Findings from Previous Studies}

In general, previous studies have found that ponds lose their effectiveness further downstream because they provide no runoff volume control and they delay and prolong peak flows (McCuen 1979; Ferguson 1995; Goff 2003; Emerson et al. 2005). Additionally, pond effectiveness is impacted by location, where ponds located in the downstream region of the watershed are typically less effective (Goff 2003; Augustine 2015). Many of the studies have therefore evaluated various watershed planning solutions that optimize the location of ponds in the watershed or optimize pond flow release controls (James et al. 1987; Shea 1996; Wulliman and Urbonas 2007; Ravazzani et al. 2014; Augustine 2015). However, both potential solutions present several limitations and concerns that can cause them to be impractical and infeasible. Thus, one common recommendation is to instead implement stormwater infiltration practices that maintain the runoff volumes and natural storage characteristics of undeveloped land (McCuen 1979; Ferguson 1995; Goff 2003; Emerson et al. 2005).

\section{Methodology}

Almost all of the previous studies on this subject have evaluated downstream ponds using synthetic design storm events or individual historical storm events. However, single event-based analyses do not provide comprehensive evaluations of the wide variety of rainfall events and initial flow conditions that can occur within a watershed. Urbonas and Glidden (1983) suggested that the use of continuous simulation to analyse the downstream impacts of ponds would present considerable merit, but it would require long term rainfall records and, at the time, a large modeling effort. Thus, the goal of this study was to analyse the impacts of ponds on downstream peak flows using long term continuous simulation modeling with 61 y of available rainfall data. Hydrologic and hydraulic model simulations were carried out using a model of the Sawmill River watershed developed using PCSWMM. Model results from a total of 903 rainfall events were evaluated to identify trends in pond effectiveness based on rainfall return period, rainfall amount, rainfall duration and initial flow conditions in the watershed.

The model was then used to carry out a sensitivity analysis by varying the maximum overland flow length (MOFL), hydraulic conductivity $(K)$, pond locations and development conditions. The impacts of modifying the MOFL and $K$ values in the watershed were evaluated because MOFL significantly impacts the timing characteristics of watershed runoff, whereas $K$ significantly impacts the amount of runoff volume discharged from the watershed. Additionally, the model was not calibrated and these watershed parameters are likely to have the highest level of uncertainty associated with their assumptions. Pond location and future development were also evaluated, as variations in pond effectiveness due to differences in pond location and pond construction sequencing have been the primary focus of many previous studies.

\subsection{Model Development}

\section{Hydrologic Model Development}

The hydrologic component of the PCSWMM model was developed by subdividing the Sawmill River watershed into 130 subwatersheds using a $1 \mathrm{~m}$ resolution digital elevation model (DEM) produced from lidar data. Watershed delineation was carried out such that each subwatershed roughly contained only one of the following land cover types: commercial, high density residential, medium density residential, high density residential, major roadway, park, quarry, forest and lake. For each subwatershed, existing land cover types (shown in Figure 3) were determined based on aerial imagery, and future land cover types (shown in Figure 4) were estimated based on proposed future development projects in the watershed that are currently being planned, including Port Wallace and expansions to Burnside. Common watershed characteristics were estimated for each land cover type, including surface roughness, imperviousness, depression storage and routing characteristics. Finally, MOFLs and average watershed slopes were estimated for each subwatershed using the lidar DEM, and soil infiltration parameters for the Green-Ampt method were estimated for each subwatershed based on provincial soil mapping. 


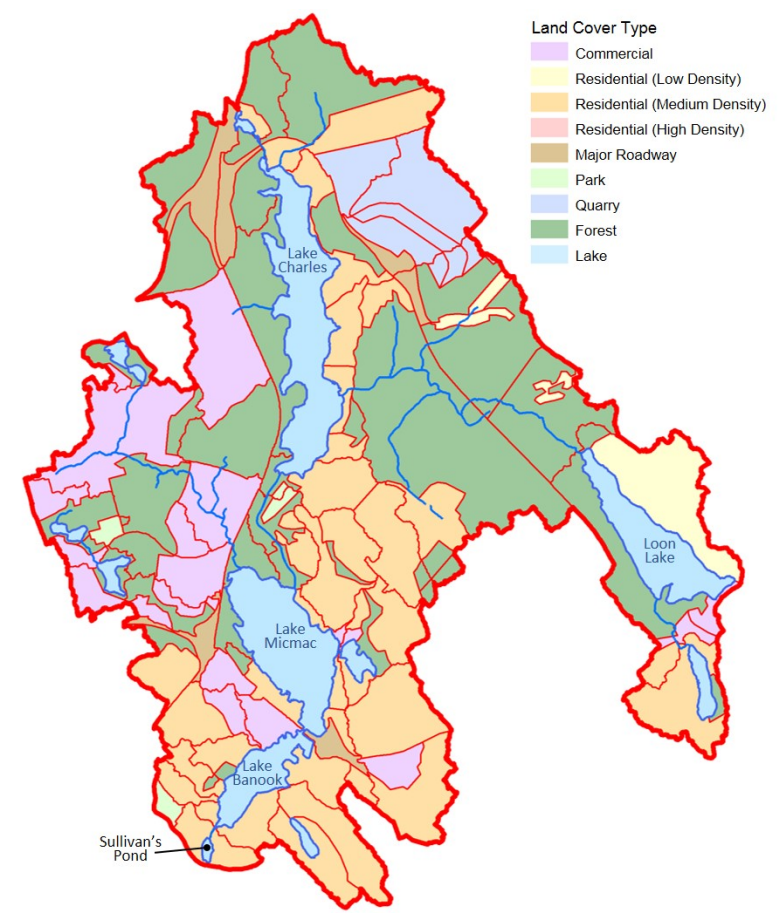

Figure 3 Existing land cover for each subwatershed.

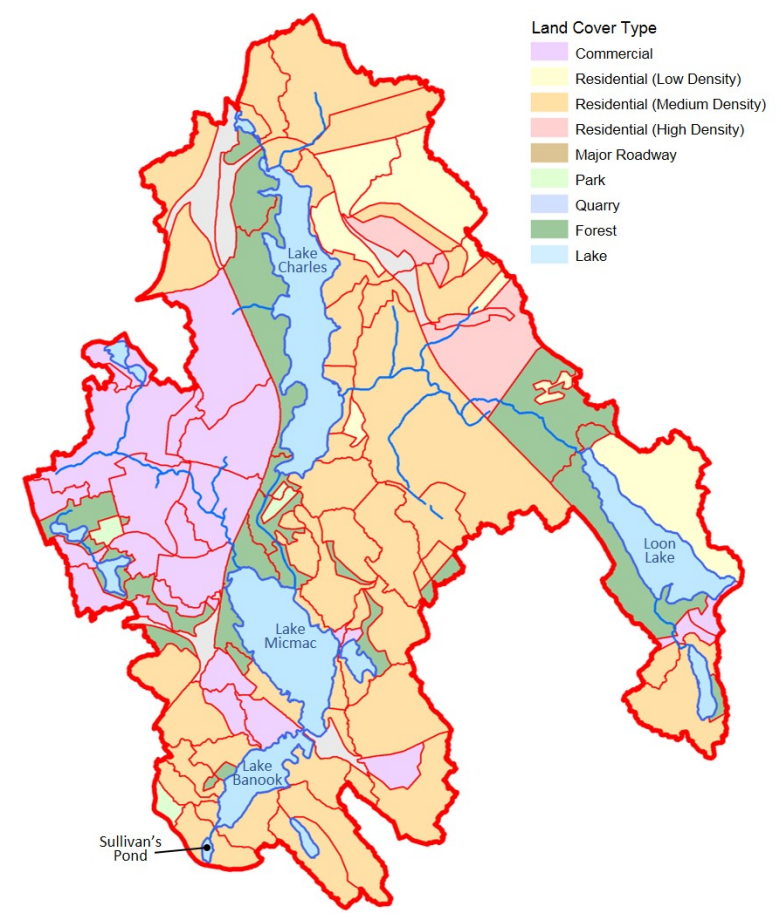

Figure 4 Future land cover for each subwatershed.

\section{Hydraulic Model Development}

The hydraulic component of the PCSWMM model was developed by inputting the various lakes, channels and hydraulic structures in the watershed based on provincial lake bathymetry maps, field measurements and the lidar DEM. All lakes were modeled in PCSWMM using depth-area storage curves.
A hypothetical stormwater management pond was then sized and input into the model for each subwatershed associated with a development land cover type (commercial, residential, major roadway, park and quarry). This approach therefore assumes the implementation of larger regional detention facilities, which, according to Mein (1980) and James et al. (1987), can be more effective at reducing downstream flows and may require less total volume than using several smaller detention facilities throughout the upstream development. A total of 78 ponds were sized for existing development conditions, and a total of 95 ponds were sized for future development conditions. Similar to the lakes, the ponds were modeled in PCSWMM using depth-area storage curves.

The ponds were sized following the most recent municipal guidelines in HRM that were available at the time of modeling, which required that pre-development peak flows be maintained under post-development conditions for the 1 in $2 y, 1$ in $5 y, 1$ in $10 \mathrm{y}$ and 1 in $100 \mathrm{y}$ storms (HRWC 2016). For each pond, an orifice was sized to control the 1 in 2 y peak flow and a weir was sized to control the 1 in 5 y, 1 in $10 y$ and 1 in 100 y peak flows. Thus, flow attenuation for storms with a return period lower than 2 y was limited to the 1 in 2 y orifice control. All pre-development and post-development peak flows were estimated by the hydrologic model, and fully forested conditions were assumed for pre-development conditions. The design rainfall events used in the hydrologic model were also developed following the municipal guidelines (HRWC 2016). Design rainfall events therefore consisted of $24 \mathrm{~h}$ duration Chicago distribution hyetographs derived from the intensity-duration-frequency (IDF) curves published by Environment Canada for the nearby Shearwater Airport climate station.

\subsection{Model Scenarios}

The model scenarios selected for the sensitivity analysis carried out for this study are summarized in Table 1.

Table 1 Model scenarios for sensitivity analysis.

\begin{tabular}{llllc}
\hline \multicolumn{1}{c}{ Scenario Group } & \multicolumn{1}{c}{ Scenario } & $\begin{array}{c}\text { Pre-Dev. } \\
\text { Conditions }\end{array}$ & $\begin{array}{c}\text { Post-Dev. } \\
\text { Conditions }\end{array}$ & $\begin{array}{c}\text { \# of } \\
\text { Ponds }\end{array}$ \\
\hline (1) Baseline & Baseline Conditions & Forested & Exist. Dev. & 78 \\
(2) MOFL Sensitivity & (a) MOFL $\times 0.1$ & Forested & Exist. Dev. & 78 \\
& (b) MOFL $\times 0.5$ & Forested & Exist. Dev. & 78 \\
& (c) MOFL $\times 2$ & Forested & Exist. Dev. & 78 \\
& (d) MOFL $\times 10$ & Forested & Exist. Dev. & 78 \\
& (a) $K \times 0.1$ & Forested & Exist. Dev. & 78 \\
(3) KSensitivity & (b) $K \times 0.5$ & Forested & Exist. Dev. & 78 \\
& (c) $K \times 2$ & Forested & Exist. Dev. & 78 \\
(4) Pond Location Sensitivty & (a) Upstream Only & Forested & Exist. Dev. & 31 \\
& (b) Downstream Only & Forested & Exist. Dev. & 47 \\
& (c) Commercial Only & Forested & Exist. Dev. & 19 \\
(5) Future Development & (a) Future Only & Exist. Dev. & Fut. Dev. & 25 \\
& (b) Future and Existing & Forested & Fut. Dev. & 95 \\
\hline
\end{tabular}




\section{Baseline Conditions}

Baseline conditions were modeled using the original estimations of watershed characteristics in the model, and it was assumed that all existing development in the watershed was controlled by regional ponds. The baseline conditions used in this study therefore simulate a hypothetical scenario where stormwater management ponds are implemented for all existing development, as opposed to simulating the actual ponds in the watershed.

\section{MOFL Sensitivity}

The MOFL sensitivity scenarios consisted of modifying the baseline estimation of MOFL in all subwatersheds by a uniform factor, followed by resizing of all ponds to the resulting watershed runoff. MOFL is often a highly uncertain watershed parameter, as the complex drainage paths that occur in a watershed are difficult to delineate at a high resolution. Thus, factors of $0.1,0.5$, 2 and 10 were selected to cover the full range of possible MOFL estimations. While MOFL values in the ranges of MOFL $\times 0.1$ and MOFL $\times 10$ were found to be unrealistically short or long, these factors were still analysed to evaluate situations where extreme MOFL values may be needed to calibrate the model. However, factors further beyond these values were considered too extreme to include in this analysis.

\section{$K$ Sensitivity}

The $K$ sensitivity scenarios consisted of modifying the baseline estimation of $K$ in all subwatersheds by a uniform factor, followed by resizing of all ponds to the resulting watershed runoff. $K$ is another highly uncertain watershed parameter, as soil infiltration properties can vary locally as well as seasonally. Thus, a factor of 0.1 was selected to analyse highly impervious soil conditions, a factor of 0.5 was selected to analyse moderately impervious soil conditions and a factor of 2 was selected to analyse pervious conditions. Factors of less than 0.1 were not analysed, as minimal infiltration was found to occur when using a factor of 0.1 . Additionally, factors above 2 were not analysed, as the associated infiltration rates were found to be unrealistically high and to result in minimal runoff.

\section{Pond Location Sensitivity}

To test the sensitivity of pond location, ponds from the baseline model were removed from selected locations in the watershed. First, the impact of implementing ponds only for existing development upstream of Lake Charles was analysed. This represents having ponds only in the upstream region of the watershed, which, according to previous studies, can be more effective at reducing downstream peak flows. Next, the impact of implementing ponds only for existing development downstream of Lake Charles was analysed. Conversely, this represents implementing ponds only in the downstream region of the watershed, which can be less effective at reducing downstream peak flows. Finally, the impact of implementing ponds only for commercial developments was analysed. This scenario best represents actual conditions in the existing watershed, as most of the existing ponds today are located in business parks such as Dartmouth Crossing and Burnside.

\section{Future Development}

The impacts of future development in the watershed were analysed for two scenarios. First, the impact of implementing ponds only in future development areas was analysed. For this scenario, the existing development conditions of the watershed were assumed to be the design pre-development conditions used for pond sizing. This best represents current pond sizing practices in the HRM, where pre-development conditions are considered to be the conditions that exist prior to the proposed development, rather than the natural forested conditions that would have existed prior to any development. Thus, for future development areas that contain existing development, pond sizes did not need to be as large using this policy. Finally, the impact of implementing ponds throughout all existing and future development was analysed following the baseline conditions policy of sizing the ponds to maintain natural forested pre-development peak flows.

\subsection{Model Simulations}

The PCSWMM model was used to perform both single design storm event simulations and long term continuous simulations for each of the above scenarios. To evaluate the effectiveness of ponds in the watershed, the model simulations were carried out under pre-development conditions, post-development conditions without ponds and post-development conditions with ponds.

\section{Design Storm Event Simulations}

Design storm event simulations were performed by inputting the $24 \mathrm{~h}$ duration 1 in $2 \mathrm{y}, 1$ in $5 \mathrm{y}, 1$ in $10 \mathrm{y}$ and 1 in $100 \mathrm{y}$ design storms. These single event simulations therefore represented the typical approach carried out by most previous modeling studies that have analysed the downstream impacts of pond detention.

\section{Continuous Simulations}

Continuous simulations were performed by inputting 61 y of hourly precipitation data collected at the Shearwater Airport climate station between 1955 and 2016. Constant low flow rates were also input into the lakes based on summer low flow measurements to account for groundwater discharge. Additional groundwater components were not included in the model simulations due to the high uncertainty associated with groundwater flow. Furthermore, seasonal variations in groundwater flow could have skewed the model results, whereas this study only intends to analyse trends associated with different types of rainfall events and with initial flow conditions that result from preceding rainfall events. Moreover, water levels in the lakes and in Sullivan's Pond have been observed to typically remain at close to their controlled levels during dry periods, with a portion of the flow seeping below the weir structures. For the purpose of this analysis, it 
was therefore assumed that additional groundwater flows were equal to the weir seepage rates.

One continuous simulation was also performed with the inclusion of snowmelt processes to assess whether they should be included in the continuous simulation analysis. Historical temperature data and wind data for the simulation period were input into the PCSWMM model, and the snowmelt parameters were calibrated to observed snow depths. Model results showed that the inclusion of snowmelt processes skewed the analysis findings, as significant flow variations occurred for storm events where snowmelt was present or where the precipitation instead fell as snow. Thus, for the purpose of identifying trends from the model results, the focus of this study was limited to rainfall events only. All historical precipitation data used in the model were therefore assumed to be rainfall data.

\subsection{Definition of Pond Effectiveness}

The ability of stormwater management ponds to attenuate post-development peak flows down to pre-development peak flow levels, or the pond effectiveness, was quantified in this study using the equation:

$$
E=\left(Q_{P O S T}-Q_{P O S T \_P O N D}\right) /\left(Q_{P O S T}-Q_{P R E}\right) \times 100 \%
$$

where:

$$
\begin{aligned}
& E=\text { pond effectiveness (\%), } \\
& Q_{\text {POST }}=\text { uncontrolled post-development peak flow, } \\
& Q_{\text {POST_POND }}=\text { controlled post-development peak flow, and } \\
& Q_{\text {PRE }}=\text { pre-development peak flow. } \\
& \text { Pond effectiveness was therefore defined for this study as }
\end{aligned}
$$
the difference between post-development peak flows with ponds (controlled) and post-development peak flows without ponds (uncontrolled), divided by the difference between post-development peak flows with ponds (controlled) and pre-development peak flows. This ratio is then presented as a percentage, where $100 \%$ would indicate that pre-development peak flows are fully maintained, and $0 \%$ would indicate that the ponds provide zero flow attenuation. Pond effectiveness values $>100 \%$ would indicate that the ponds attenuate peak flows to below pre-development peak flow levels, and pond effectiveness values $<0 \%$ would indicate that the use of ponds further increases post-development peak flows. Pond effectiveness was evaluated for this study immediately downstream of the ponds, where peak flow attenuation is maximized, and further downstream at Sullivan's Pond, where attenuation is reduced.

Previous studies have used various methods for evaluating the downstream impacts of ponds. Some studies only compared post-development peak flows with and without ponds (McCuen 1974; Mein 1980; Emerson et al. 2005), while other studies compared pre-development peak flows to post-development peak flows with and without ponds (Urbonas and Glidden 1983; Ferguson 1995; Goff 2003). For almost all previous studies, the percentage increase in peak flows was calculated as the basis for discussing model results. However, to quantify the ability of ponds to maintain downstream pre-development peak flows, percentage increases would need to be calculated for both post-development conditions with ponds and post-development conditions without ponds. Instead, the pond effectiveness definition used in this study considers all three peak flows (pre-development, post-development without ponds and post-development with ponds) in a single term, which therefore simplifies the ability to compare the large numbers of storm events occurring in long term simulations.

\subsection{Binning of Model Results}

The continuous simulation model results for the various scenarios were then grouped into bins such that the results could be analysed and compared based on different criteria. The bins were selected by grouping events with similar rainfall return periods, events with similar rainfall amounts, events with similar rainfall durations, and events with similar initial flows in Sullivan's Pond. Average values were then calculated for each bin such that trends could be identified between the bins. Only rainfall events that had an estimated return period of greater than 1 in 2 months were analysed, which included a total of 903 rainfall events during the 61 y period.

\section{Results}

Model results for baseline conditions were analysed by evaluating the peak flows at Sullivan's Pond (Figure 5) and by evaluating the pond effectiveness both at Sullivan's Pond and the upstream ponds based on rainfall return period (Figure 6), rainfall amount (Figure 7), rainfall duration (Figure 8) and initial flow conditions (Figure 9).

Model results for the remaining scenarios were analysed by evaluating the pond effectiveness at Sullivan's Pond based on rainfall return periods only. MOFL sensitivity results are presented in Figure 10, K sensitivity results are presented in Figure 11, pond location sensitivity results are presented in Figure 12, and future development results are presented in Figure 13. In Figures 5 through 13, the bars represent the average values for each bin whereas the faded dots represent the results from the individual rainfall events. Each figure is discussed within the appropriate section below.

\subsection{Baseline Model Results}

\section{Peak Flow Results}

As shown in Figure 5, both the design event simulations and continuous simulations showed that the use of ponds to control runoff from all upstream development does not successfully reduce the downstream peak flows to pre-development levels. Instead, the pond-controlled peak flows (blue) typically lie somewhere between the pre-development peak flows (orange) and post-development peak flows (green). 


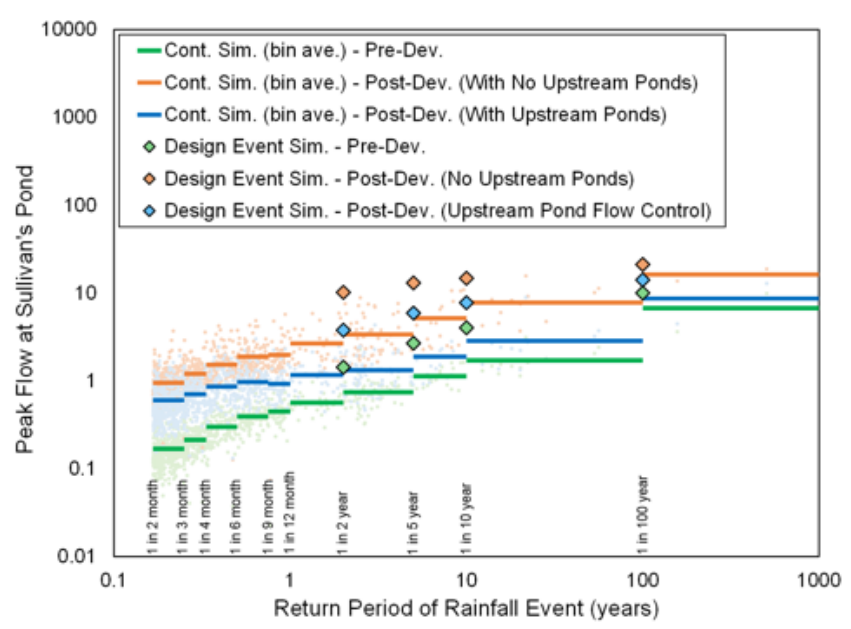

Figure 5 Peak flows at Sullivan's Pond.

\section{Pond Effectiveness Results: Rainfall Return Period}

As shown in Figure 6, both the design event simulations and the continuous simulations found that pond effectiveness was significantly reduced at Sullivan's Pond (blue) compared with the upstream ponds (red), confirming the findings from the previous studies. For example, the average pond effectiveness from the continuous simulations was $86 \%$ at the upstream ponds and $55 \%$ at Sullivan's Pond and the average pond effectiveness from the event simulations was $100 \%$ at the upstream ponds and $68 \%$ at Sullivan's Pond. Moreover, the pond effectiveness at Sullivan's Pond was $<90 \%$ for $98 \%$ of the rainfall events in the continuous simulations, indicating that the peak flows at Sullivan's Pond were increased for almost all rainfall events despite the use of upstream ponds. This finding is further illustrated by the binned pond effectiveness values shown in Figure 6 for Sullivan's Pond, which ranged from $45 \%$ to $86 \%$.

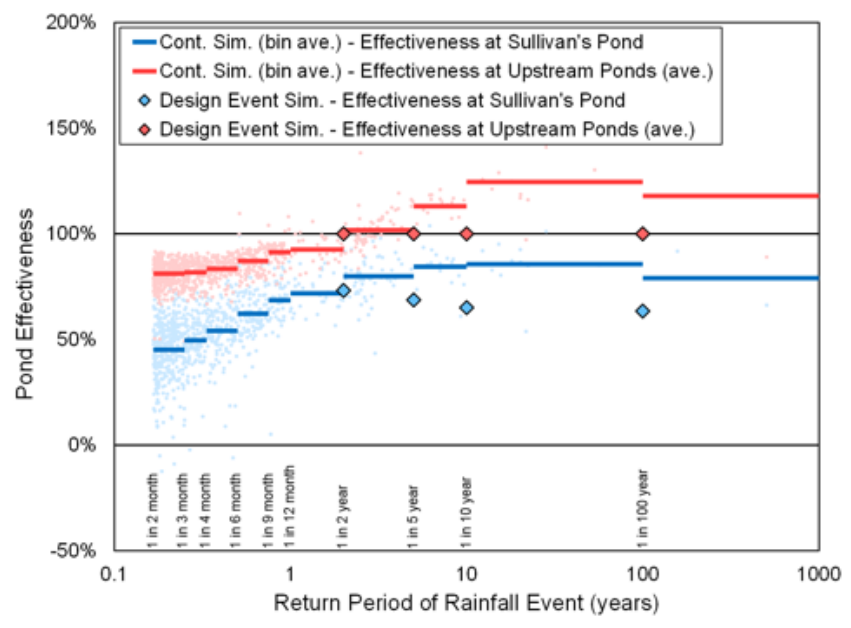

Figure 6 Pond effectiveness for various rainfall return periods.

Pond effectiveness from the continuous simulations was found to increase with higher return periods at the upstream ponds and Sullivan's Pond, indicating that this trend originates at the upstream ponds. For example, average pond effectiveness at the upstream ponds was found to be $<100 \%$ for historical rainfall events with return periods below 1 in $2 \mathrm{y}$. This is because the upstream ponds were only designed to attenuate 1 in $2 y$ rainfall events or higher, which caused the runoff from smaller rainfall events to pass through the pond outlet orifices without being fully attenuated. However, average pond effectiveness at the upstream ponds was found to be $>100 \%$ for historical rainfall events with return periods greater than 1 in $2 \mathrm{y}$. This is mostly because the pond outlets were sized to $24 \mathrm{~h}$ duration storm events, which caused additional attenuation to occur for shorter duration storms with higher intensities. As a result, pond effectiveness was also found to be lower during the design storm events compared to during the historical storm events for similar return periods.

\section{Pond Effectiveness Results: Rainfall Amount}

As shown in Figure 7, similar trends occurred for rainfall amount as for rainfall return period, as the upstream ponds were only designed to attenuate larger storm events with rainfall amounts $>81 \mathrm{~mm}$ and rainfall durations of $24 \mathrm{~h}$. Thus, pond effectiveness was found to increase with higher rainfall amounts, but was significantly reduced for smaller storm events. However, as shown by the scatter data of the individual rainfall events in Figure 7, pond effectiveness values that are considerably $>100 \%$ at the upstream ponds were observed during rainfall events $<100 \mathrm{~mm}$. When comparing this to the return period results in Figure 6, it is observed that the pond effectiveness was highest for return periods above 1 in $2 \mathrm{y}$ and rainfall amounts $<100 \mathrm{~mm}$. Thus, pond effectiveness was greatest for the high intensity and low to moderate volume rainfall events.

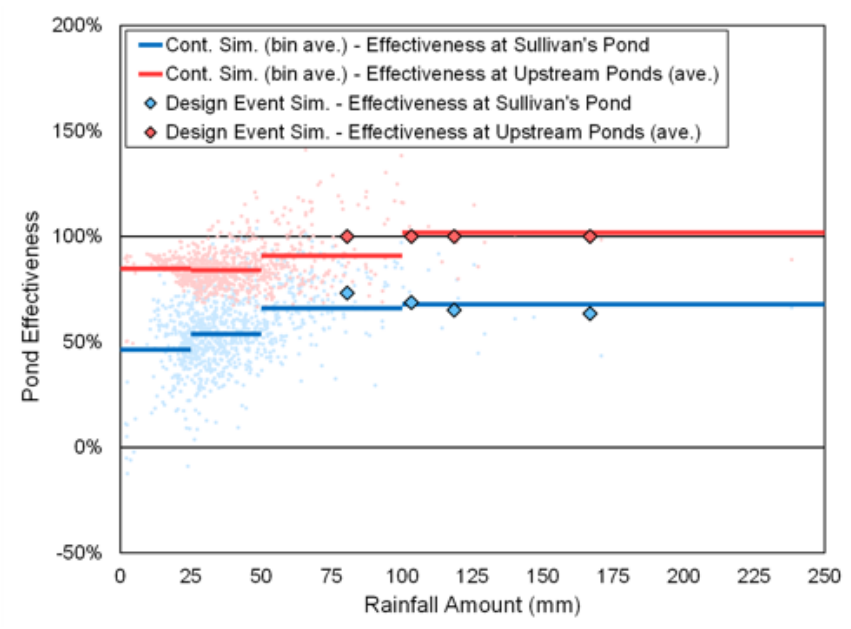

Figure 7 Pond effectiveness for various rainfall amounts.

\section{Pond Effectiveness Results: Rainfall Duration}

As shown in Figure 8, pond effectiveness was found to decrease with higher rainfall durations. Again, this was because the upstream ponds were only designed for $24 \mathrm{~h}$ storm events, so the ponds provided additional attenuation for shorter duration 
storm events that had higher intensities. It should be noted that all historical rainfall events that had a return period of less than 1 in 2 y were omitted from the rainfall duration bin average calculations shown in Figure 8. As previously discussed, lower pond effectiveness values occurred during the smaller and more frequent storm events. Since these storm events typically had shorter rainfall durations, inclusion of the smaller storm events would have skewed the rainfall duration trends observed in Figure 8.

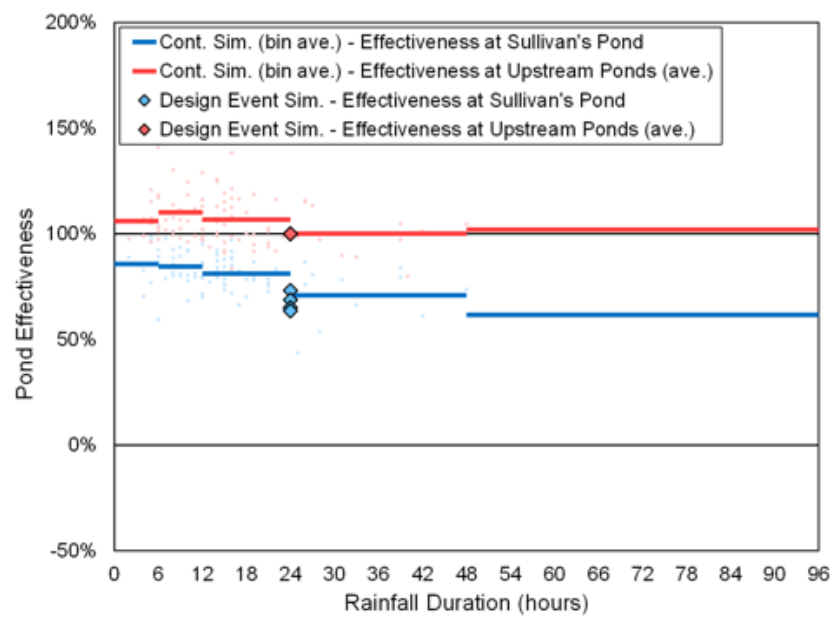

Figure 8 Pond effectiveness for various rainfall durations.

Pond Effectiveness Results: Initial Flow

As shown in Figure 9, pond effectiveness was found to decrease with higher initial flows in Sullivan's Pond. When initial flows were $>0.5 \mathrm{~m}^{3} / \mathrm{s}$ in the continuous simulations, average pond effectiveness values at Sullivan's Pond were $<50 \%$. For initial flows $>1 \mathrm{~m}^{3} / \mathrm{s}$, pond effectiveness was further reduced to $35 \%$. These findings suggest that the flows generated from one rainfall event can greatly impact the ability of ponds to attenuate downstream flows during a subsequent rainfall event. This is an important observation because ponds delay flow and increase runoff volumes, indicating that they can also increase the amount of flow in the watershed at the beginning of subsequent storm events. Additionally, since runoff from most of the upstream development is collected by Lake Charles, Lake Micmac and Lake Banook before it is discharged to Sullivan's Pond, these lakes provide natural flow attenuation and delay peak flows, which further increases the interaction of flows from rainfall events with flows from subsequent rainfall events. Thus, if a small storm event were to occur the day before a large storm event, the pond effectiveness at Sullivan's Pond could be significantly reduced, increasing the risk of flooding. The impact of successive rainfall events on pond effectiveness was found to be minimal at the upstream ponds, as the ponds empty their storage volumes much sooner than the downstream lakes.

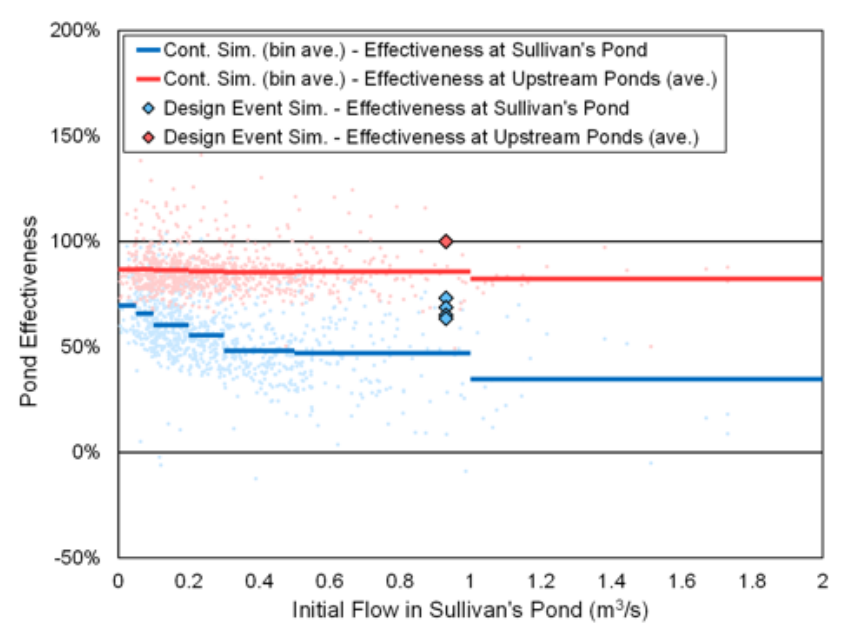

Figure 9 Pond effectiveness for various initial flows.

\subsection{MOFL Sensitivity Results}

As shown in Figure 10, pond effectiveness was found to be drastically reduced for decreased flow lengths such as MOFL $\times 0.1$ (green) due to peak flows throughout the watershed peaking at closer to the same time. However, for increased flow lengths such as MOFL $\times 10$ (red), the higher MOFL values resulted in larger pond volumes and time of concentrations, which further delayed the peak flows to Sullivan's Pond. While these delayed peak flows increased pond effectiveness during the event simulations, they sometimes reduced pond effectiveness during the continuous simulations since they created higher initial flow conditions during successive rainfall events. Due to the counteraction of these two phenomena occurring during the continuous simulations, the increased flow lengths had an overall minimum impact on the average pond effectiveness values shown in Figure 10.

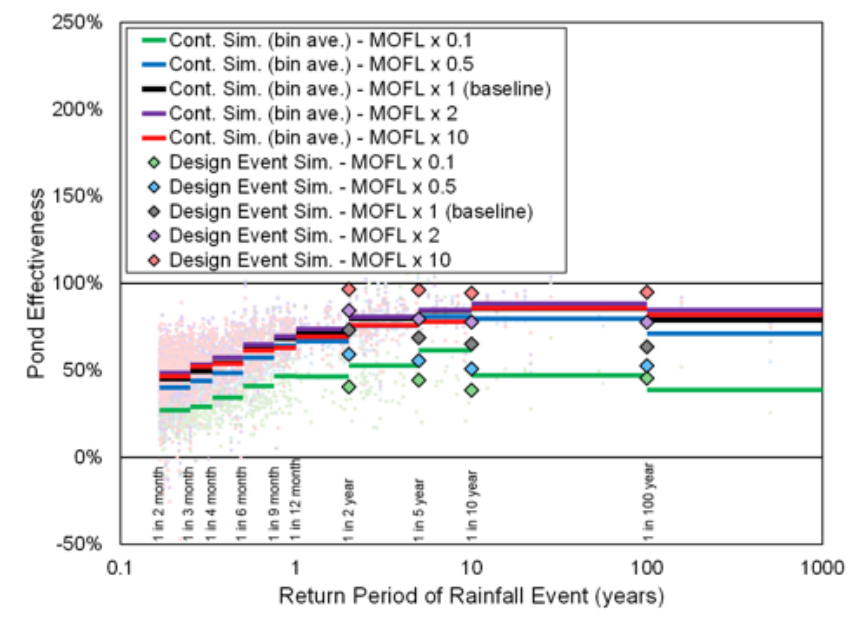

Figure 10 Impact of MOFL on pond effectiveness.

\subsection{K Sensitivity Results}

As shown in Figure 11, pond effectiveness was found to be drastically reduced for decreased conductivity values such as 
$K \times 0.1$ (green), which was again due to peak flows throughout the watershed occurring at close to the same time. However, for increased conductivity values such as $K \times 2$ (red), a large reduction in pond effectiveness only occurred during the historical rainfall events. This was because the higher $K$ values resulted in lower estimates of pre-development peak flows when sizing the ponds, which was due to the increased infiltration associated with natural watershed conditions. Thus, the larger pond volumes caused longer delays in peak flows, which increased the interaction of flows with subsequent rainfall events during the continuous simulations.

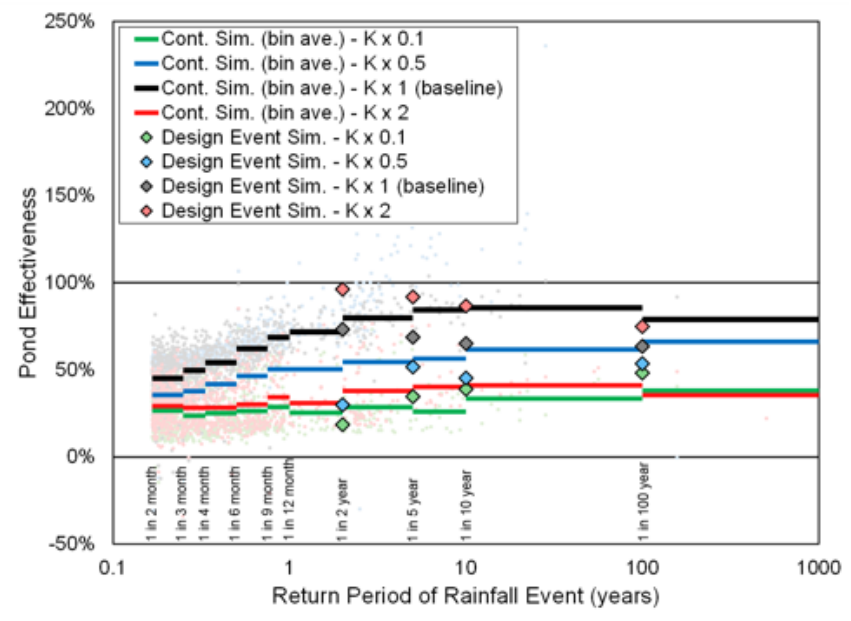

Figure 11 Impact of $K$ on pond effectiveness.

\subsection{Pond Location Sensitivity Results}

As shown in Figure 12, pond effectiveness was slightly reduced when ponds were only located downstream of Lake Charles (green). While this reduction was minor, it confirmed the findings of previous studies that suggested that ponds are less effective when located in the downstream region of the watershed due to the delayed and prolonged peak flows compounding with flows from the upper region of the watershed (Goff 2003; Augustine 2015). However, pond effectiveness was found by the continuous simulation results to be significantly reduced when ponds were only located upstream of Lake Charles (blue). This was because all flow control was removed from the downstream region, which caused uncontrolled short duration peak flows to be discharged to Sullivan's Pond. Thus, when ponds were located only in the upstream region, pond effectiveness was only increased for the larger storm events that had longer storm durations, such as during the 1 in 5 y, 1 in $10 \mathrm{y}$ and 1 in $100 \mathrm{y}$ design storm events. Similar results were found for when ponds were located only in commercial development areas (red), where the delayed peak flows from the ponds would generally occur later than the peak flows from the rest of the watershed, while minimal flow control was available to attenuate short duration peak flows in the downstream region.

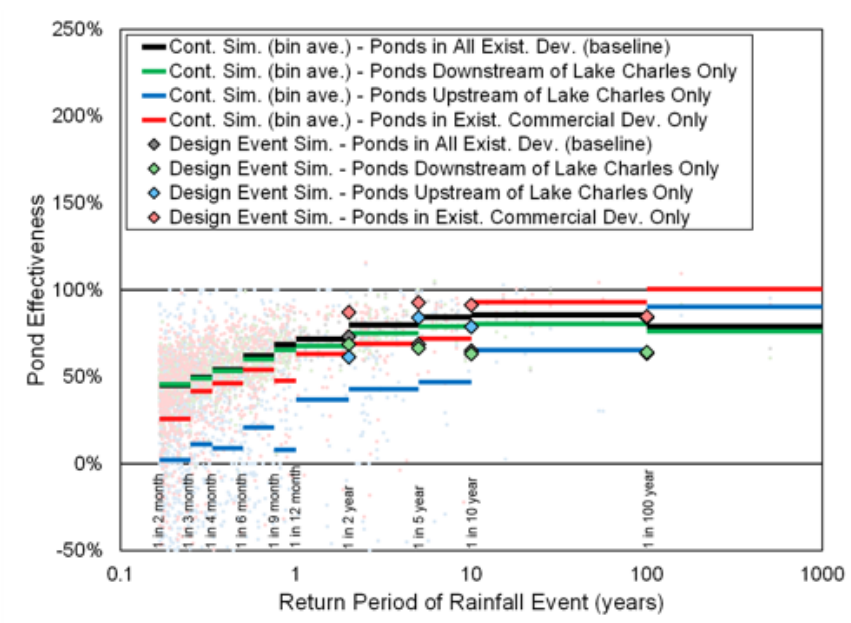

Figure 12 Impact of pond location on pond effectiveness.

\subsection{Future Development Sensitivity Results}

As shown in Figure 13, similar results occurred for when ponds were located only in future development areas (green) as for when ponds were only located upstream of Lake Charles. This was because most of the estimated future development in the watershed was also located upstream of Lake Charles. The delayed peak flows from the ponds generally occurred later than the peak flows from the rest of the watershed, while minimal flow control was available to attenuate the short duration peak flows in the downstream region. Finally, implementing ponds in all existing and future development (red) resulted in a minimal increase in pond effectiveness when compared to implementing ponds only in existing development. This was also because the estimated future development was mostly located within the upper region of the watershed. However, this finding also indicates that the peak flows at Sullivan's Pond would be increased by future development if ponds were used to manage stormwater runoff, as average pond effectiveness for this scenario ranged between $43 \%$ and $85 \%$.

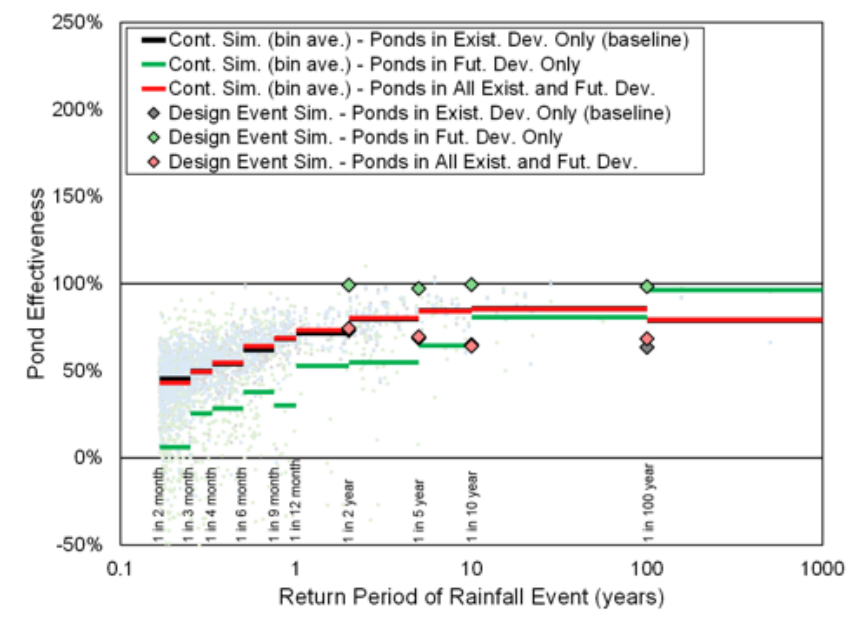

Figure 13 Impact of future development on pond effectiveness. 


\section{Conclusions and Recommendations}

\subsection{Summary of Findings}

This study used long term continuous simulation modeling to evaluate the ability of stormwater management ponds located throughout the Sawmill River watershed to control peak flows downstream at Sullivan's Pond. According to the model results, the flow attenuation provided by the upstream ponds was reduced downstream at Sullivan's Pond, confirming the general findings of previous studies. During the 903 simulated rainfall events, the average effectiveness of the ponds to maintain pre-development peak flows was $86 \%$ immediately downstream of the ponds, whereas the average effectiveness was reduced to $55 \%$ at Sullivan's Pond. The results also found that the upstream ponds were less effective at attenuating downstream peak flows during smaller rainfall events, longer rainfall events, and rainfall events that occurred when higher initial flows were present in the watershed. Furthermore, the delayed and prolonged peak flows discharged by the ponds were found to increase initial flows during subsequent rainfall events, further reducing their attenuation benefits.

When the MOFL and $K$ watershed parameters were increased in the model, the required pond volumes increased. This increased the delay of peak flows discharged from the ponds and therefore also increased the initial flows in the watershed during subsequent rainfall events. However, when MOFL and $K$ values were decreased, peak flows in the watershed occurred at close to the same time. Thus, both increasing and decreasing these two watershed parameters decreased the ability of ponds to maintain downstream peak flows.

When ponds were located only in the downstream region of the watershed, the delayed peak flows from the ponds compounded with flows from the upstream watershed. However, having ponds in the upstream region of the watershed alone was found to improve flow attenuation at Sullivan's Pond only during large rainfall events, as no attenuation was provided for the shorter duration peak flows occurring in the downstream watershed. This finding also applies if ponds are to be implemented only in future development areas, as most future development was estimated to be located in the upstream region. If ponds were instead implemented for all existing and future development, the additional ponds in the future development areas would have minimal impact attenuating downstream peak flows. Future development would, however, increase peak flows at Sullivan's Pond for both scenarios.

\subsection{Recommendations for Future Modeling}

Since this study only evaluated the use of hypothetical ponds in the Sawmill River watershed, an analysis of actual conditions was not included. However, similar to the work performed by Emerson et al. (2005), an analysis of actual conditions could be carried out by collecting detailed information on all existing ponds in the watershed and by collecting flow data. After the existing ponds are included in the model, the model could then be calibrated to the historical flow records. While the range of MOFL and $K$ values evaluated in the study simulated possible calibration scenarios, a calibrated model would provide a more representative baseline model for the analysis. However, it is likely that a calibrated model would still produce the same general trends identified in this study for the different rainfall characteristics.

Since initial flow conditions in the Sawmill River watershed were found to greatly influence the model results, model calibration should also include interflows, or runoff that first infiltrates into the ground before resurfacing into the lakes or streams. These slower flows were not accounted for in the model used for this study due to the high uncertainty and variation associated with subsurface flows. However, because of their slower timing characteristics, the inclusion of interflows would likely result in higher initial flow conditions during consecutive rainfall events that could impact pond effectiveness. Other processes that would also need to be accounted for in the model calibration are snowmelt, groundwater and lake evaporation. These factors were either not included or kept at a constant rate in this study since they would introduce more variability in the model results.

Finally, this study presented trends based on continuous simulation model results only for a single watershed, and the watershed analysed in this study consisted of a chain of lakes controlled by weirs along the main drainage path. Continuous simulation could therefore be used to evaluate other watersheds or, similar to Ferguson (1995), randomized synthetic watersheds to determine more generalized results.

\subsection{Implications for Stormwater Management}

Maintaining the pre-development peak flows throughout a watershed using stormwater management ponds has remained a significant challenge over the past several decades, as no general pond control policies or pond location planning strategies proposed from previous studies have been found to be fully effective, practical and feasible (McCuen 1974; Shea 1996; Augustine 2015). Furthermore, this study showed how the ability of ponds to attenuate downstream peak flows can vary significantly based on the characteristics of the rainfall event and the initial flow conditions in the watershed. Pond effectiveness can also vary between watersheds (Goff 2003) and for different locations in the watersheds (Augustine 2015), resulting in a need to develop stormwater management pond strategies that are specific to each watershed. For example, the priority for a watershed that uses ponds to manage stormwater may be to maintain peak flows at a specific location where there are high risks of flooding or other environmental impacts, while allowing for peak flows to increase at other locations. In the Sawmill River watershed, an example of such a priority could be to maintain the peak flows to Sullivan's Pond during major storm events to protect the Downtown Dartmouth area from flooding. To achieve this objective using strategic pond controls, flow attenuation in the upstream region 
of the watershed would be increased and flow attenuation in the downstream region of the watershed would be decreased. However, the larger ponds required for increased flow attenuation may be infeasible and create unbalanced development policies, whereas the decreased flow attenuation may create additional flood, erosion and water quality concerns within the watershed. This approach also does not prevent the increased runoff volumes discharged by the stormwater management ponds from increasing the initial flow conditions during subsequent storm events, which can further increase flood risks. Furthermore, the approach only focuses on flood prevention during major storm events without consideration for the environmental impacts of reduced attenuation during smaller storm events.

To better negate the impacts of development on stormwater runoff, several of the previous studies of stormwater management ponds have recommended the use of alternative stormwater management practices that preserve the natural storage of undeveloped land and that maintain runoff volumes in addition to peak flows (McCuen 1979; Ferguson 1995; Goff 2003; Emerson et al. 2005). By maintaining the pre-development hydrograph (peak flows, runoff volumes and timing characteristics) of the flows discharged from each development area within a watershed, the downstream peak flows would, in theory, remain the same. Preserving runoff volumes would also prevent an increase in downstream bank erosion that would otherwise be caused by the sustained higher flow rates discharged from ponds (McCuen 1979).

Approaches to stormwater management that aim to preserve pre-development site hydrology (such as LID) have become more common over the past two decades due to growing concerns about runoff volumes, stream erosion, groundwater recharge, water quality, aesthetics and space requirements associated with conventional stormwater management ponds. Additionally, whereas this study showed how ponds provide poor flow attenuation during more frequent rainfall events, approaches that instead focus on preserving site hydrology typically use infiltration practices that maintain or reduce peak flows during these smaller rainfall events in an effort to maintain annual runoff volumes. However, while maintaining the natural pre-development hydrographs at the source would be ideal, more field-based research is needed on the impacts of common infiltration practices on peak flows and runoff volumes at a watershed scale, as research to date has mostly focused on modeling efforts (Zimmer et al. 2007; Shannak 2014; Ahiablame and Shakya 2016; Juan et al. 2016).

Future development in the Sawmill River watershed (such as the developments currently proposed for Port Wallace and Burnside) should consider the impacts of downstream peak flows when designing stormwater management since this study found that the use of conventional stormwater management ponds would continue to increase the peak flows discharged to Sullivan's Pond. This increase can be prevented if the natural hydrology of each new development site is preserved and approaches such as LID can be used to help preserve site hydrology through infiltration, evapotranspiration and rainwater harvesting practices in addition to runoff detention. Additionally, whereas the implementation of stormwater management ponds for all existing development was found to only partially reduce downstream peak flows towards pre-development levels, retrofitting these areas with LID practices would instead help to restore the natural runoff volumes of the watershed and, as a result, could be more effective in restoring the pre-development peak flows at Sullivan's Pond.

\section{References}

Ahiablame, L. and R. Shakya. 2016. "Modeling Flood Reduction Effects of Low Impact Development at a Watershed Scale." Journal of Environmental Management 171:81-91.

ASCE. 1917. "Final Report of the Special Committee on Floods and Flood Prevention." Transactions of the American Society of Civil Engineers 81 (1): 1218-34.

Augustine, A. J. 2015. Evaluation of Spatially Dependent On-Site Detention Basin Policies. Fort Collins, CO: Colorado State University. Master's thesis.

Del Giudice, G., R. Gargano, G. Rasulo and D. Siliciano. 2014. “Preliminary Estimate of Detention Basin Efficiency at Watershed Scale." Water Resources Management 28 (4): 897-913.

Emerson, C. H., C. Welty and R. G. Traver. 2005. "Watershed-Scale Evaluation of a System of Storm Water Detention Basins." Journal of Hydrologic Engineering 10 (3): 237-42.

Ferguson, B. K. 1995. “Downstream Hydrographic Effects of Urban Stormwater Detention and Infiltration." In Proceedings of the 1995 Georgia Water Resources Conference, 128-31. Atlanta, GA: Georgia Institute of Technology. https://smartech.gatech.edu/handle/1853/43424

Goff, K. M. 2003. A Sensitivity Analysis of the Influence of Watershed and Development Characteristics on the Cumulative Impacts of Stormwater Detention Ponds. Knoxville, TN: University of Tennessee. MSc thesis.

HRWC (Halifax Regional Water Commission). 2016. Design and Construction Specifications (Water, Wastewater and Stormwater Systems), 2016 Edition. Halifax, NS: Halifax Regional Water Commission https://www.halifax.ca/sites/default/files/documents/ home-property/water/2016\%20Design\%20and\%20Construction\%20Specifications.pdf

Hawley, M. E., T. R. Bondelid and R. H. McCuen. 1981. “A Planning Method for Evaluating Downstream Effects of Detention Basins." Journal of the American Water Resources Association 17 (5): 806-13.

James, W. P., J. F. Bell and D. L. Leslie. 1987. "Size and Location of Detention Storage." Journal of Water Resources Planning and Management 113 (1): 15-28. https://doi.org/10.1061/(ASCE)0733-9496(1987)113:1(15)

Juan, A. J., C. Hughes, Z. Fang and P. Bedient. 2016. “Hydrologic Performance of Watershed-Scale Low-Impact Development 
in a High-Intensity Rainfall Region." Journal of Irrigation and Drainage Engineering 143 (4): 04016083.

Mays, L. W. and P. B. Bedient. 1982. "Model for Optimal Size and Location of Detention." Journal of Water Resources Planning and Management 108 (3): 270-85.

McCuen, R. H. 1974. "A Regional Approach to Urban Storm Water Detention." Geophysical Research Letters 1 (7): 321-2.

McCuen, R. H. 1979. “Downstream Effects of Stormwater Management Basins." Journal of the Hydraulics Division 105 (11): 1343-56.

Mein, R. G. 1980. "Analysis of Detention Basin Systems." Journal of the American Water Resources Association 16 (5): 824-9.

Ravazzani, G., P. Gianoli, S. Meucci and M. Mancini. 2014. “Assessing Downstream Impacts of Detention Basins in Urbanized River Basins Using a Distributed Hydrological Model." Water Resources Management 28 (4): 1033-44.

Shannak, S. A. 2014. Modeling the Effects of Low Impact Development Practices on Streams at the Watershed Scale. College Station, TX: Texas A\&M University. PhD dissertation.
Shea, C. C. 1996."Reduction of Downstream Impacts Through Use of Variable Detention Basin Volume Requirements." In North American Water and Environment Congress \& Destructive Water, 1858-63. Reston, VA: American Society of Civil Engineers.

http://cedb.asce.org/CEDBsearch/record.jsp?dockey $=0102367$

Urbonas, B. and M. W. Glidden. 1983. “Potential Effectiveness of Detention Policies." Presented at the Southwest Storm Drainage Symposium, Texas A \& M, November, 1983. https://udfcd.org/wp-content/uploads/uploads/resources/ technical\%20papers/Potential\%20Effectivness\%20of\%20 Detention\%20Policies.pdf

Wulliman, J., and B. Urbonas. 2007. “Peak Flow Control for a Full Spectrum of Design Storms." NOVATECH 2007:1115-22.

Zimmer, C. A., I. W. Heathcote, H. R. Whiteley and H. Schroeter. 2007.“Low-Impact-Development Practices for Stormwater: Im-plications for Urban Hydrology." Canadian Water Resources Journal 32 (3): 193-212. 